\title{
SEROPREVALENCIA DE Neospora caninum EN BOVINOS LECHEROS DEL VALLE DE LIMA
}

\author{
Pablo Silva S. ${ }^{1}$, Amanda Chávez V., ${ }^{2,}$, Hermelinda Rivera G. ${ }^{2}$ y Eva Casas A. ${ }^{2}$
}

\section{Abstract}

The aim of the present study was to determine the seroprevalence of Neospora caninum in dairy cattle at the Lima Valley in year 2000. A total of 304 sera samples from dairy cows of 19 herds located in the northern (12 herds) and southern (7) part of Lima were analysed to detect antibodies against $N$. caninum using the immunofluorescense indirect test. $29.6 \pm 5.1 \%(90 / 304)$ of the animals showed antibodies at the 1:200 dilution. The prevalence in the northern area was $40.8 \pm 8.8 \%(49 / 120)$, whereas in the southern area was $22.3 \pm 6.0 \%(41 / 184)$. All farm had seropositives animals to $N$. caninum. The results confirm the presence of $N$. caninum in dairy herds of the Lima valley.

Key words: bovine, Neospora caninum, IFAT, seroprevalence, antibodies, dairy herd

\section{Resumen}

El objetivo del presente estudio fue determinar la seroprevalencia de Neospora caninum en bovinos lecheros del valle de Lima en el año 2000. Se evaluaron 304 sueros de vacas lecheras adultas provenientes de 19 establos lecheros ubicados en la zona norte $(n=12)$ y en la zona sur $(n=7)$ del valle de Lima, para detectar anticuerpos contra $N$. caninum mediante la prueba de inmunofluorescencia indirecta. El 29.6 $\pm 5.1 \%(90 / 304)$ de los animales presentó anticuerpos contra el parásito en una dilución de 1:200. La prevalencia en la zona norte fue de $40.8 \pm 8.8 \%$ (49/120), mientras que en la zona sur fue de $22.3 \pm 6.0 \%(41 / 184)$. Todos los establos evaluados presentaron algún animal seropositivo a $N$. caninum. Estos resultados confirman la presencia de $N$. caninum en bovinos lecheros del valle de Lima.

Palabras clave: bovinos, Neospora caninum, IFI, seroprevalencia, anticuerpos, lecherías

\footnotetext{
${ }^{1}$ Práctica privada. E-mail: vetpablo@yahoo.com.ar

${ }^{2}$ Laboratorio de Microbiología y Parasitología, FMV-UNMSM

${ }^{3}$ E-mail: a_chavez_g@hotmail.com.pe
} 


\section{INTRODUCCIÓN}

Entre los problemas que producen mayores pérdidas económicas a nivel pecuario se encuentran los reproductivos, destacando los abortos de diversa etiología (Anderson et al., 1994). En los últimos años se ha identificado al parásito Neospora caninum como uno de los principales agentes infecciosos causantes de problemas reproductivos en ganado bovino lechero. El $N$. caninum pertenece a un nuevo género de la familia Sarcocystidae, del phylum Apicomplexa y está estrechamente relacionado al Toxoplasma gondii (Holmdahl et al. 1994).

El aborto, principal signo clínico producido por este parásito en el ganado bovino, se puede presentar en cualquier momento de la gestación, aunque con mayor frecuencia entre el cuarto y sexto mes de gestación (Anderson et al., 1994). También puede provocar la muerte de terneros neonatos o nacimiento de animales enfermos con signos nerviosos, o el nacimiento de otros sin infección aparente, los cuales pueden comportarse como diseminadores de la enfermedad dentro del hato (Schares et al., 1998; Dubey, 1999). La única forma de transmisión reconocida en bovinos es la vertical de madre a cría, vía trasplacentaria. La transmisión horizontal en cambio, es frecuente en caninos (Björkman et al., 1996; Bergeron et al., 2000).

Estudios iniciales en nuestro país indican que los problemas reproductivos, entre los que destacan los abortos, son frecuentes en algunos hatos lecheros del valle de Lima y que Neospora caninum se encuentra presente en el $62 \%$ de vacas que abortan (Rivera et al., 2000). El objetivo de este trabajo fue determinar la seroprevalencia del parásito Neospora caninum en bovinos lecheros del valle de Lima.

\section{Materlales y Métodos}

\section{Procedencia de las Muestras}

El presente estudio se llevó a cabo en bovinos lecheros de crianza intensiva de dos zonas del valle de Lima. La zona norte comprendida entre los kilómetros 0 y 150 de la carretera Panamericana Norte, hasta la provincia de Huacho, y la zona sur comprendida entre los kilómetros 0 y 150 de la carretera Panamericana Sur, hasta la provincia de Cañete. El área de muestreo se encontró entre los 0 a $500 \mathrm{msnm}$, con un clima templado con temperaturas máximas de $28^{\circ} \mathrm{C}$ y mínimas de $12^{\circ} \mathrm{C}$ y con una humedad relativa cercana al $95 \%$.

\section{Muestras}

Las muestras evaluadas fueron obtenidas durante el año 2000 y pertenecieron al banco de sueros del Laboratorio de Virología de la Facultad de Medicina Veterinaria de la Universidad Nacional Mayor de San Marcos. Las muestras fueron seleccionadas al azar de 19 establos con una población total de 4,410 vacas.

\section{Detección de Anticuerpos contra Neospora caninum}

Los anticuerpos contra Neospora caninum en las muestras de suero diluidas en 1:200 fueron detectados mediante la prueba de inmunofluorescencia indirecta (Fig.1). Se utilizó un kit comercial (VMRD, USA) y se siguió el protocolo descrito por la empresa.

\section{Resultados y Discusión}

El $29.6 \pm 5.1 \%(90 / 304)$ de las muestras evaluadas presentaron anticuerpos contra $N$. caninum (Cuadro 1). Todos los establos evaluados presentaron animales 


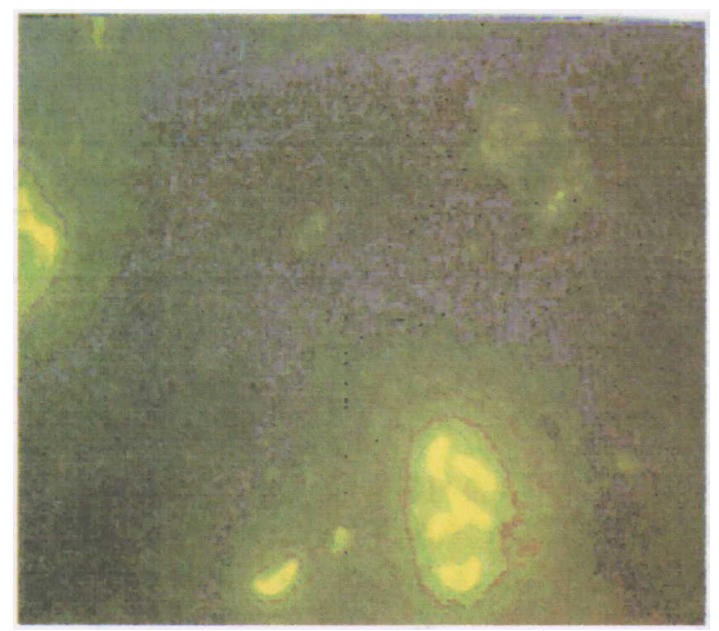

Figura 1. Taquizoitos de Neospora caninum demostrados mediante inmunofluorescencia indirecta

reactores positivos, con prevalencias que variaron entre 3.3 a $64.7 \%$. La prevalencia en los establos de la zona norte fue de $40.8 \pm$ $8.8 \%(49 / 120)$ mientras que los de la zona sur mostraron una prevalencia de $22.3 \pm 6.0 \%$ (41/184).

La zona norte de Lima presentó en estudios previos una tasa de abortos cercana al $35 \%$, debido principalmente al virus BVD (Rivera, H., Comunicación personal). Este precedente podría haber influido en la alta prevalencia de neosporosis en la zona, tomando como referencia un estudio previo donde se asoció la presencia de Neospora caninum e infección concomitante con virus BVD (Björkman et al., 2000); ya que otros factores de riesgo como la presencia de perros en los establos, raza y edad de las vacas, y tipo de explotación estuvieron presentes en iguales condiciones en todos los establos bajo estudio. Otra posibilidad sería la introducción de animales seropositivos. En un estudio del Reino Unido se demostró que la trasmisión vertical fue del $95.2 \%$; es decir, vacas seropositivas tienen mayor probabilidad de producir terneros infectados (Davison et al., 1999); condición que conlleva a perpetuar la infección en el hato.
Estudios preliminares detectaron la presencia de anticuerpos contra $N$. caninum en el $42.9 \%$ de vacas en Cajamarca (Cabrera et al., 2000), y en el 57\% en Arequipa (Andresen, H., Comunicación personal). Por otro lado, en otro estudio preliminar se detectó la presencia de quistes de $N$. caninum en 16 de 29 fetos abortados, lo cual confirmaría que la neosporosis se encuentra presente en el país y es causa de abortos en vacas lecheras del valle de Lima (Rivera et al., 2000). Los resultados del presente estudio corroborarían la presencia de $N$. caninum en el valle de Lima.

En otros países de América del Sur se ha confirmado la presencia del parásito, reportándose prevalencias de $14.1 \%$ en Brasil, al evaluarse 447 sueros provenientes de vacas lecheras de la ciudad de Bahía (Gondim et al., 1999) y de 56.9\% en Argentina (Campero et al., 1998); en ambos casos utilizando la prueba de inmunofluorescencia indirecta. En vacas que tuvieron problemas de aborto en Escocia, se encontró una prevalencia de 59\% (Buxton et al., 1997). En Taiwán se reportó una prevalencia de $44.9 \%$ (Ooi et al., 2000) y en un estudio serológico en un establo lechero de Australia, después de una racha de abortos, se encontró una prevalencia de $24 \%$ (Atkinson et al., 2000). Estos resultados demuestran que el parásito Neospora caninum se encuentra distribuido en todo el mundo. 
Cuadro 1. Detección de anticuerpos contra Neospora caninum en establos lecheros del valle de Lima. 2000

\begin{tabular}{|c|c|c|c|c|}
\hline \multirow{2}{*}{$\begin{array}{l}\text { Zona de } \\
\text { Lima }\end{array}$} & \multirow{2}{*}{ Establo } & \multirow{2}{*}{$\begin{array}{l}\text { Muestras } \\
\text { (n) }\end{array}$} & \multicolumn{2}{|c|}{ Seropositivos } \\
\hline & & & (n) & $\%$ \\
\hline \multirow{13}{*}{ Norte } & 1 & 14 & 4 & 28.6 \\
\hline & 2 & 17 & 9 & 52.9 \\
\hline & 3 & 25 & 10 & 40.0 \\
\hline & 4 & 7 & 4 & 57.1 \\
\hline & 5 & 17 & 11 & 64.7 \\
\hline & 6 & 5 & 1 & 20.0 \\
\hline & 7 & 3 & 1 & 33.3 \\
\hline & 8 & 6 & 2 & 33.3 \\
\hline & 9 & 11 & 2 & 18.2 \\
\hline & 10 & 6 & 2 & 33.3 \\
\hline & 11 & 7 & 1 & 14.3 \\
\hline & 12 & 2 & 1 & 50.0 \\
\hline & Subtotal & 120 & 49 & $40.8 \pm 8.8^{1}$ \\
\hline \multirow{9}{*}{ Sur } & 13 & 45 & 14 & 31.1 \\
\hline & 14 & 47 & 10 & 21.3 \\
\hline & 15 & 14 & 5 & 35.7 \\
\hline & 16 & 8 & 4 & 50.0 \\
\hline & 17 & 19 & 5 & 26.3 \\
\hline & 18 & 21 & 2 & 9.5 \\
\hline & 19 & 30 & 1 & 3.3 \\
\hline & Subtotal & 184 & 41 & $22.3+6.0^{1}$ \\
\hline & Total & 304 & 90 & $29.6+5.1^{1}$ \\
\hline
\end{tabular}

${ }^{1}$ Porcentaje \pm Intervalo de confianza

Todos los establos evaluados presentaron animales con títulos de anticuerpos contra $N$. caninum, lo que sugiere que la gran mayoría de establos lecheros en el valle de Lima presentan una fuente de infección aún no determinada. Sin embargo, la presencia de anticuerpos contra el parásito en un animal no indica que $N$. caninum represente la causa de los problemas reproductivos; aunque vacas seropositivas con anticuerpos contra el parásito, tienen mayor probabilidad de tener problemas de aborto o nacimientos de terneros infectados congénitamente (Wouda et al.,1998).

\section{Lrrmatura Crada}

1. Anderson, M.L.; B.C. Barr; P.A. Conrad. 1994. Protozooal causes of reproductive failure in domestic ruminants. Vet. Clin. North. Am. Food. Anim. Pract. 10: 439-461.

2. Atkinson, R.A.; R.W. Cook; L.A. Reddacliff; J. Rothwell; K.W. Broady; P.A.W. Harper; J.T. Ellis. 2000. Seroprevalence of Neospora caninum infection following an abortion outbreak in dairy cattle herd. Aust. Vet. J. 78: 262-266. 
3. Bergeron, N.; G. Fecteau; J. Paré; R. Martineau; A. Villeneuve. 2000. Vertical and horizontal transmission of Neospora caninum in dairy herds in Québec Can. Vet. J. 41: 464-467.

4. Björkman, C.; O. Johansson; S. Stenlund; O. Joakim; A. Uggla. 1996. Neospora species infection in a herd of dairy cattle. J. Am. Vet. Med. Assoc. 208: 1441-1444.

5. Björkman, C.; S. Alenius; U. Emanuelsson; A. Uggla. 2000. Neospora caninum and Bovine Virus Diarrhoea Virus infections in Swedish dairy cows in relation to abortion. Vet. J. 159: 201-206.

6. Buxton, D.; G.L. Caldow; S.W. Maley; J. Marks; E.A. Innes. 1997. Neosporosis and bovine abortion in Scotland. Vet. Rec. 141: 649-651.

7. Cabrera, M.; P. Ortiz; J. Claxton; D. Williams; A. Trees. 2000. Evidencia serológica de infección por Neospora caninum en ganado vacuno en Perú. Res. IV Congreso Peruano de Parasitología. p 212.

8. Campero, C.M.; M.L. Anderson; G. Conosciuto; H. Odriozola; $G$. Bretschneider; M.A. Poso. 1998. Neospora caninum-associated abortions in a dairy herd in Argentina. Vet. Rec. 143: 228-229.

9. Davison, H.C.; A. Otter; A.J. Trees. 1999. Estimation of vertical and horizontal transmission parameters of Neospora caninum infections in dairy cattle. Int. J. Parasitol. 29: 1683-1689.
10. Dubey, J.P. 1999. Recent advances in Neospora and neosporosis. Vet. Parasitol. 84: 349-367.

11. Gondim, L.F.P.; I.F. Sartor; M. Hasegawa; I. Yamane. 1999. Seroprevalence of Neospora caninum in dairy cattle in Bahia, Brazil. Vet. Parasitol. 86: 71-75.

12. Holmdahl, O.J.; J.G. Mattsson; A. Uggla; K.E. Johansson. 1994. The phylogeny of Neospora caninum and Toxoplasma gondii based on ribosomal RNA sequences. FEMS Microbiol. Lett. 119: 187-192.

13. Ooi, H.K.; C.C. Huang; C.H. Yang; S.H. Lee. 2000. Serological survey and first finding of Neospora caninum in Taiwan, and the detection of this antibodies in various body fluids of cattle. Vet. Parasitol. 90: 47-55.

14. Rivera, H.; D. Nelson; L. Tabacchi. 2000. Neospora caninum y otros agentes en fetos abortados de bovinos lecheros del valle de Lima. Rev. Inv. Vet. Perú 11: 1-7.

15. Schares, G.; M. Peters; R. Wurm; A. Bärwald; F.J. Conraths. 1998. The efficiency of vertical transmission of Neospora caninum in dairy cattle analysed by serological techniques. Vet. Parasitol. 80: 87-98.

16. Wouda, W.; A.R. Moen; Y.H. Schukken. 1998. Abortion risk in progeny of cows after a Neospora caninum epidemic. Theriogenology 49: 1311-1316. 